Journal of Southeast Asian

\title{
Appendix B: Focus Group Summary of the Laotian American Orgnization
}

Leslie Chanthaphasouk

University of California at Los Angeles, Ichanthaphasouk@gmail.com

\section{Recommended Citation}

Chanthaphasouk, Leslie (2011) "Appendix B: Focus Group Summary of the Laotian American Orgnization," Journal of Southeast Asian American Education and Advancement. Vol. 6 : Iss. 1, Article 3.

DOI: $10.7771 / 2153-8999.1019$

Available at: https://docs.lib.purdue.edu/jsaaea/vol6/iss1/3

This document has been made available through Purdue e-Pubs, a service of the Purdue University Libraries. Please contact epubs@purdue.edu for additional information.

This is an Open Access journal. This means that it uses a funding model that does not charge readers or their institutions for access. Readers may freely read, download, copy, distribute, print, search, or link to the full texts of articles. This journal is covered under the CC BY-NC-ND license. 


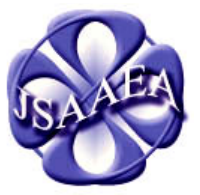

Volume 6 (2011)
Journal of Southeast Asian American

Education \& Advancement

WWW.JSAAEA.org
A peer-reviewed

\title{
Southeast Asian American Education 35 Years After Initial Resettlement:
} Research Report and Policy Recommendations

Conference Report of the National Association for the Education and Advancement of Cambodian, Laotian, and Vietnamese Americans

\section{APPENDIX B}

\section{Focus Group Summary of the Laotian American Organization}

\author{
Leslie Chanthaphasouk \\ University of California at Los Angeles
}

Note: This summary is a combination of the results of the focus groups I conducted with members of SEACLEAR, a retention project catering towards the needs of Southeast Asian students at UCLA, along with my own research on the educational experiences of Lao Americans.

\section{Focus Group Summary of the Southeast Asian Education and Retention (SEACLEAR)}

\section{Southeast Asian Student Education (K-12): Access, Assessment, and Accountability}

Tracking. Southeast Asian students were placed on either high or low academic tracks. Many of those who made it to UCLA as freshman were placed on high tracks and given special opportunities to advance their academic interests. Others who were placed on the low track often stayed there and were given remedial courses, or placed in special education courses, which tends to alienate students from the rest of their peers. There was also little room for advancement from low track to high track.

Lack of cultural understanding by teachers and administrators. One of the participants brought up the differences in the value system that is instilled in students during their K-12 experience as opposed to cultural values, especially in regards to parent participation. For instance, according to schools, the common expectation of a "good parent" is someone who

\footnotetext{
(a) SORERIIGHISRESERVED Readers are free to copy, display, and distribute this article, as long as the work is attributed to the author(s) and the Journal of Southeast Asian American Education \& Advancement, it is distributed for noncommercial purposes only, and no alteration or transformation is made in the work. More details of this Creative Commons license are available at $\mathrm{http}: / /$ creativecommons.org/licenses/by-nc-nd/3.0/. All other uses must be approved by the author(s) or JSAAEA.
} 
attends parent-teacher conferences, volunteers at student activities and is well informed of their child's educational experiences. At home, however, a good parent is also someone who works various jobs to support the family in other ways, which often leaves little to no time to get involved directly with the child's education. Students are likely to feel alienated from their peers and feel that their parents are inadequate or don't care about their education. This can also be attributed to the lack of Southeast Asian educators and administrators who are more likely to understand the cultural background of these students and inform others about how to deal with these issues.

Racial stereotyping Southeast Asians are often subjected to various stereotypes: the Asian "nerd," the Asian "gangster," and the English Language Learner (ELL), all of which have negative effects. The Asian "nerd" stereotype, also called the Model Minority Myth, places high expectations of academic success on all students of Asian descent, regardless of background. Students who do not fulfill these expectations tend to fall through the cracks and are deemed insufficient due to their own lack of effort instead of lack of support systems. For those who did achieve high academic success, however, their efforts were not attributed to hard work, but rather to their Asian descent. One participant noted, "I really wanted to be Mexican because when they got C's, and they got praise for it." Contrarily, Asian "gangsters" are often seen as inferior to their other Asian counterparts, labeled as "bad kids," and often assigned to remedial courses. These courses don't allow them to become prepared for college, or boost their confidence for pursuing their dreams in the future. Lastly, some participants noted they were automatically placed in ESL classes simply because they were Asian. These stereotypes often breed feelings of inferiority and self-hate. One participant noted that being Asian American meant you were either ignored, or that you are given a lot of attention.

Violence/racial tension. Violence in the community is a big concern for Southeast Asians growing up in various urban cities. One participant noted that violence in her high school often distracted students from the learning process, especially if there is police presence on campus. Many students, including SEA students, opted for gangs because of their environmental conditions. Some of the violence was also attributed to racial tension at the schools, which were not addressed or mediated by administrators as much as they should have been.

\section{Other Findings}

Military recruiters. A large presence of military recruiters is attributed to the low number of SEAs who seek higher education. These military recruiters often seek people of color who do not have a specific path they are going to take after high school graduation and are attracted by promises of money for college. One participant noted that an (Asian) military recruiter openly harassed students who said they were going to college, saying it lacked stability compared to joining the military.

Lack of Southeast Asian LGBT support: One participant noted that there was a lack of support systems for LGBT students in the K-12 system, which could contribute to mental health issues, as highlighted by the recent teen gay suicides in the news. 


\section{Southeast Asian Higher Education Access and Opportunities}

Affordability. The most important barrier for access to higher education is the concept of affordability. Many Southeast Asian students and parents feel college is too expensive, especially if the child wants to go to a 4-year university directly after high school. Many are unaware that college can be affordable after financial aid and/or scholarships. Others are wary of taking out loans without the guarantee of a financially stable future. A key suggestion would be to create a scholarship fund specifically for Southeast Asians.

Concern for financial stability. According to the participants, some of their SEA peers opted to work directly after college because of financial issues with the family, especially if the family owns a business and wants the child to help with the business. Others have seen older cousins or siblings head into the work force right after high school and see money as the main motivation as opposed to delaying gratification (and conversely spending a lot of money) to pursue higher education. As a consequence, many do not focus on academics because they intend on working after high school.

Familial responsibility. Very similar to the previous point, some students feel selfish by going to college when they have a responsibility to provide for their family by working or helping out at the family business. One participant noted that when he goes home from college, he feels lost and disconnected from his family and does not know how to help them.

Lack of college going culture. One participant noted that there was a lack of a college going culture at his high school; students were expected to simply graduate high school. This can also be attributed to a lack of role models or those who had previously attended conference. This also reflects the lack of outreach efforts focused on these schools, which often have a majority of people of color.

Pressure to succeed. As the first in their family to attend college, many feel pressure to succeed in what they do and often have the dilemma of choosing a major that would make a lot of money for the family, or doing something they love and/or getting involved with the community. As a result, some pick up majors based on financial outlook, though their strengths are not in the field. According to a retention counselor, some have dropped out or were subject to dismissal due to this pressure and lack of academic progress.

Extracurricular activities allow for exploration of self. Unlike K-12 education, higher education has provided additional opportunities for students to explore who they are and where they come from. The existence of ethnic organizations and political advocacy groups allow them to learn more about their history, community, and community conditions. However, some feel disappointed that they had been living most of their life not knowing the truth about their community conditions.

Increased in relevant education. Higher education has also provided additional opportunities for students to take classes about their history and life experiences in ethnic or area studies, though the classes are very limited compared to other disciplines. Many 
wished there were more classes that spoke to their history and experiences. There is also a lack of Southeast Asian language programs.

Work/life balance. Some student leaders stressed that they have difficulty balancing academics and community, which leads to their grades dropping in classes. This retention project provides a support network to ensure a healthy work/life balance.

\section{My Research on Educational Experiences of Lao Americans}

UCLA is a selective university, so low enrollment numbers might also be a reflection of high admission standards, which is true. Most Lao American students actually attend California State Universities or community colleges. Results also show that students are ill prepared for the CSU level.

\section{Key Barriers to Lao American Educational Achievement}

\section{Need for financial security.}

a. Parents/students not aware of resources or affordability of college might deter those from entering higher education, especially entering a 4-year university right after high school.

b. Students may feel obligated to contribute financially to the family, especially for families who own businesses. Inability to balance work, school, and family may deter them from their studies.

c. Students see others who worked right after high school and are motivated by the thought of making money (instead of paying money to go to college), and thus do not make an effort to do well in high school.

d. Recommendations:

i. Support efforts that help distribute literature and run workshops in the community to make sure parents and students know about financial aid and other resources that help make college affordable.

ii. Create support networks for students who need help balancing their workload. (I.e. Peer counseling, mentorship groups, etc.)

iii. Let students know the advantages in investing in their education and the importance of delayed gratification.

Generation Gap. The effects of war and trauma have created a large generation gap between parents and their children. Key barriers to educational achievement include:

a. Language Barrier/Lack of understanding of the American school system:

The language barrier, differences in the American education system, and, for some, low levels of education often hinder parents from becoming more engaged in their child's educational experience. Many students are thus forced to navigate the education system by themselves. Without this support network from their parents, 
and lack of agencies or organizations to provide that support, some end up getting lost along the way.

b. Recommendations:

i. Create more heritage language programs for second-generation students to better communicate with their parents.

ii. More courses on SEA history to foster intergenerational understanding.

iii. Print school materials in SEA languages so parents can become more engaged in their child's educational experience.

\section{Racial stereotyping.}

a. The model minority myth speculates that all Asians are destined to succeed with hard work and time. Those who do not conform to the stereotype are simply dismissed as not working hard enough, ignoring other structural causes of their lack of achievement. These students aren't getting the support they need to excel academically.

b. Lao Americans and other Southeast Asians are also stereotyped as thugs, gangsters, pregnant teens, or simply, "bad kids" and are often placed in low-track remedial courses. These courses often alienate them from the rest of the student body, and provide little support for gaining proficiency in core subjects.

c. Teachers are unaware of these students' needs and/or the conditions at the students' home, and again don't provide the academic and emotional support needed in the classroom.

d. Recommendations:

i. Create specific support programs to help students who are not succeeding in regular classes to get up to speed with their peers. These courses/programs should be temporary only, and should simply work towards integrating students back into mainstream classes that prepare them for college, instead of trapping them in low-track remedial courses.

ii. Administer cross-cultural training for all teachers, informing them of the specific challenges faced by SEA students, and how to address these challenges with support inside the classroom.

iii. Create a monitoring system for at-risk students who may fall through the cracks. Most of the time, these students need the support the most, but are often overlooked for qualified students who show more academic promise. As a result, they lose confidence in themselves and their future.

Lack of role models. There is a serious absence of role models, especially educators and professionals in the Lao American community, which can be attributed to the lack of professional networks and/or resources for advancement after graduation.

\section{Concluding Thoughts on the Lao American Community \& Outlook towards the Future}

In a quick evaluation of the past 35 years, the Southeast Asian community has made large strides in adapting to life in America, but some have had difficulties progressing on issues such as educational attainment. Many of the difficulties of the Lao American community 
specifically, I believe, are tied to the fact that Lao Americans are still seeking an identity, even after all these years in America. When we were resettled, we were "spread like ashes" across the United States. Because of this, we currently lack visibility compared to the Vietnamese, Cambodian, or Hmong communities across the country. (Though there are large Lao communities in California, Minnesota, and Virginia, they are often overlooked due to the existence of other larger Southeast Asian communities nearby.) This lack of visibility can be attributed the large ethnic diversity of Lao refugees who arrived in America (including Lao, Hmong, Khmu, Mien, Tai Dam, Tai Lue, and other ethnic groups), which often diffuses coalition building and can also explain the lack of mobilization on the local and national level.

I believe that establishing a common identity is a key to pushing forward progress for the Lao American community. In order to see change occur on the local and national levels, we need to ask ourselves, "What does it mean to be Lao?" Answering this question will help us begin to solve the issues that are standing in the way of educating our future generation. If no one knows we are, how do teachers help out? If the second generation does not know their history (because it is not taught in the classroom), how do they understand their parents? And most importantly, how does the community move forward, if we don't understand our past? These are key questions that I ask current and potential leaders of the Lao American and Southeast Asian community.

I also want to make a point that we are not here to simply point fingers on the education system, the teachers, or other people for the issues affecting our communities. In order for us to progress, we must collaborate with policy makers, educators, academics, practitioners, elected officials, families, parents, and students alike. We must make a collective effort into creating sustainable solutions so that we can all move forward, one step at a time.

\section{About the Author}

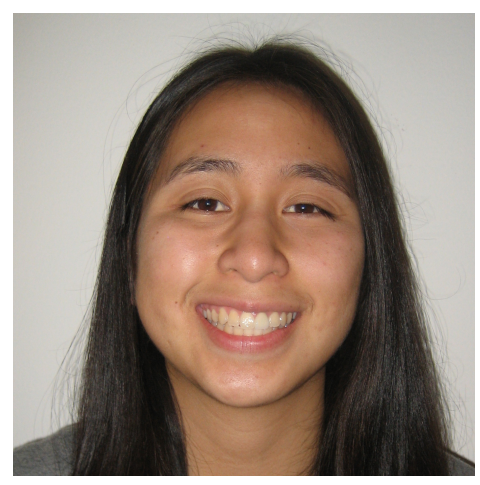

Leslie Chanthaphasouk is a recent graduate of the University of California, Los Angeles (UCLA) having received a Bachelor of Arts degree in International Development Studies and Asian American Studies in June 2010. Her area of interest is in Southeast Asian American history and education. In May 2008 Leslie founded the Laotian American Organization (LAO) at UCLA along with two other Lao American student leaders. The organization's main goal is to bring visibility to the various issues that affect Laotian Americans and to advocate for the needs of the community. Currently, Leslie is a Program Coordinator for College Bound, a college outreach program aimed to increase educational opportunities for people of color and first generation college students at the Orange County Asian Pacific Islander Community Alliance based in Orange County, California. 